\title{
Agricultura e urbanização na paisagem do município de São José-SC (Séculos XVIII A XX)
}

\section{Agriculture and urbanization in São José landscape (from 18th to 20th century)}

\section{Marlon Brandt ${ }^{1}$}

Resumo: $O$ artigo tem por objetivo analisar as transformações da paisagem do município de São José, SC, partindo da ocupação açoriana no século XVIII, até a intensificação do crescimento urbano e adensamento demográfico na década de 1970, modificando espaços que antes assumiam uma feição caracteristicamente rural em bairros densamente povoados.

Palavras-chave: paisagem, agricultura, urbanização, São José - SC.
Abstract: This article aims to analyze the transformations of the landscape of São José, SC, from the Azorean immigration in the $18^{\text {th }}$ century, to the increasing urban growth and population density after the 1970 s, modifying areas that were once typically rural, into densely populated ones.

Keywords: landscape, agriculture, urbanization, São José - SC.

As alterações impostas ao meio ambiente através da ação humana têm reduzido o mundo natural a "entornos domesticados, aparados e moldados para se adequarem a algum uso prático ou à estética convencional", cujo resultado mais visível se reflete na paisagem. Assim, um estudo sob o viés da geografia histórica do do município de São José, SC, privilegiou a análise da sua paisagem, partindo da ocupação açoriana no século XVIII, até a intensificação do crescimento urbano e adensamento demográfico que se faz sentir nos municípios vizinhos à Florianópolis, capital do Estado, a partir da década de 1970, transformando espaços, que antes assumiam uma feição caracteristicamente rural, em bairros densamente povoados.

Estudar as transformações da paisagem e as relações entre os homens e a natureza, integrando as características e os elementos tanto

1 Doutor em História, professor do curso de Geografia - Licenciatura da Universidade Federal da Fronteira Sul, campus Chapecó. E-mail: marlon.brandt@uffs.edu.br.

${ }^{2}$ DEAN, W. A ferro e fogo: a história e a devastação da Mata Atlântica brasileira. São Paulo: Companhia das Letras, 2004, p. 23-24.

Fronteiras: Revista Catarinense de História [on-line], Florianópolis, n.23, p.7-20, 2014. 
físicos quanto humanos ${ }^{3}$ no passado, implica em se unir, neste enfoque, o tempo e o espaço, pois, como afirma Chris Philo, "a complexa geografia do mundo está estreitamente ligada com o que acontece em sua história" ${ }^{4}$. É necessário, entretanto, considerar não apenas os fenômenos de materialidade óbvia, mas também os fenômenos de natureza "imaterial", que compreende "todo um conjunto de acontecimentos passageiros (guerras, fomes), entidades abstratas e estruturas mais profundas". Ou seja, o pesquisador, como afirma Maurício de Almeida Abreu, não deve se "ater apenas aos vestígios concretos que ele deixou, isto é, as formas materiais que ainda subsistem na paisagem".

Paisagem que, de acordo com Milton Santos, é a expressão materializada do espaço geográfico, sendo "o conjunto das formas que, num dado momento, exprimem as heranças que representam as sucessivas relações entre o homem e a natureza" , e que para Roberto Lobato Corrêa e Zeny Rosendahl, é resultado da "ação, ao longo do tempo, da cultura sobre a paisagem natural"’ . Portanto, a ação do homem, conforme Carl Sauer, se expressa na paisagem, tornando-se assim uma paisagem cultural, sujeita a mudanças, seja pelo desenvolvimento de uma cultura, pelo contato de diferentes culturas ou pela substituição de culturas ${ }^{8}$.

O litoral catarinense é caracterizado pela existência de uma planície litorânea relativamente curta, sobretudo na porção central do Estado, caracterizada pela presença de solos arenosos, ácidos e pobres, apresentando vegetação de restinga e da Floresta Ombrófila Densa ${ }^{9}$. Essas formações

${ }^{3}$ CAVAlCANTI, A. P. B.; VIADANA, A. G.. Análise da paisagem como base para a organização do espaço geográfico. In: IV Seminário Latinoamericano de Geografia Física. Anais... Maringá/PR: Editora da UEM, 2006. v. 1. p. 15-28.

${ }^{4}$ PHILO, C. História, geografia e o "mistério ainda maior" da geografia histórica. In: GREGORY, D., MARTIN, R., SMITH, G. (orgs). Geografia humana: sociedade, espaço e ciência social. Rio de Janeiro: Zahar, 1996, p. 270-274.

${ }^{5}$ ABREU, M. de A.. A apropriação do território no Brasil colonial. In: CASTRO, Iná Elias; GOMES, P. C. C; CORREAA, R. L. (orgs). Explorações geográficas: percursos no fim do Século. Rio de Janeiro: Bertrand Brasil, 1997, p. 240.

${ }^{6}$ SANTOS, M. A natureza do espaço: técnica e tempo, razão e emoção. 4. ed. São Paulo: Hucitec, 2006, p. 103-104.

7 CORREAA, R. L.; ROSENDAHL, Z. Apresentando leituras sobre paisagem, tempo e cultura. In: CORREA, Roberto Lobato; ROSENDAHL, Zeny (orgs) Paisagem, Tempo e Cultura. 2. Ed. Rio de Janeiro: UERJ, 2004, p. 9.

${ }^{8}$ SAUER, C. Morfologia da Paisagem. In: CORRÊA, R. L.; ROSENDAHL, Z. (Orgs). Paisagem, tempo e cultura. 2. Ed. Rio de Janeiro: Ed. UERJ, 2004, p. 43

${ }^{9}$ VEADO, R. W. A. Geossistemas de Santa Catarina. In: GERARD, L. H. O; MENDES, I. A. (Orga.). Teoria, técnicas, espaços e atividades. Temas em geografia contemporânea. Rio Claro: Editora UNESP, 2001.

Fronteiras: Revista Catarinense de História [on-line], Florianópolis, n.23, p.7-20, 2014. 
vegetais compõem um complexo de tipo de florestas que é conhecida genericamente como Mata Atlântica brasileira ${ }^{10}$.

A partir do século XVI e XVII, a ocupação vicentista passou a promover comparação a população autóctone que habitava o litoral, um maior uso dessa formação vegetal, em virtude de suas atividades agrícolas e pecuárias. Porém foi principalmente a partir da presença açoriana, após o século XVIII conforme aponta Nazareno José de Campos, que a região assumiu sua feição sócio-cultural básica, tendo por base uma economa de subsistência, em sua fase inicial, passando também a uma posterior fundamentação econômica de pequena produção mercantil com cacacterísticas agrícola-pesqueira ${ }^{11}$.

Autores como Walter Piazza ${ }^{12}$ e Vilson Francisco de Farias ${ }^{13}$ mencionam a instalação de açorianos nas terras do vale do rio Maruim, seus afluentes e outros pequenos rios, em áreas onde atualmente se encontram bairros como o Centro, Praia Comprida, Roçado e Barreiros. Inicialmente esses imigrantes buscaram reproduzir, nos novos espaços, as técnicas com as quais estavam habituados, insistindo no cultivo de cereais como o trigo, a aveia e o centeio. Porém encontraram nessas terras condições ambientais adversas para o cultivo e a farinação desses produtos, de clima temperado e mediterrâneo, em um ambiente subtropical e mais úmido com solos pobres em nutrientes, fatores limitantes para o maior desenvolvimento da agricultura na região ${ }^{14}$. Como estratégia de sobrevivência, adotaram o cultivo de produtos nativos, como a mandioca, além do milho e do feijão, cana-de-açúcar, café, abóbora, melancia, amendoim, frutas em geral e inclusive arroz e algodão, que inclusive estava ligado à produção artesanal de tecidos ${ }^{15}$. Vilson Francisco de Farias ${ }^{16}$ apresenta um relatório da produção econômica da Capitania de Santa Catarina, realizado no ano de 1796, onde é possível constatar a produção de 20.000 alqueires de farinha

${ }^{10}$ DEAN, W.. Op. Cit.

${ }^{11}$ CAMPOS, N. J de.. São José: faces do rural no transcorrer histórico. In: CAMPOS, N. J de; BRANDT, M.; CANCELIER, J. W. (Orgs.). O Espaço rural de Santa Catarina: novos estudos. Florianópolis: Ed. da UFSC, 2013.

12 PIAZZA, W.. A epopéia açórico-madeirense 1748-1756. Florianópolis: Editorra Lunardelli/Ed.da UFSC, 1992

${ }^{13}$ FARIAS, Vilson Francisco de. São José: 250 anos. 3. Ed. São José: Edição do autor, 2001.

${ }^{14}$ LAGO, P. F. Gente da terra catarinense - desenvolvimento e educação ambiental. Florianópolis: UFSC/FCC/Lunardelli/UDESC, 1988. VEADO, R. W. A. Geossistemas de Santa Catarina. 1998, 349 fl. Tese (Doutorado em Geografia) - Instituto de Geociências e Ciências Exatas, Universidade Estadual Paulista, Campus de Rio Claro, Rio Claro, 1998.

${ }^{15}$ CAMPOS, N. J de. Op. Cit.

${ }^{16}$ FARIAS, V. F. de. São José: 250 anos. 3. Ed. São José: Edição do autor, 2001.

Fronteiras: Revista Catarinense de História [on-line], Florianópolis, n.23, p.7-20, 2014. 
de mandioca, 6.619 alqueires de arroz, 2.749 alqueires de milho, 1.005 alqueires de feijão e apenas 121 alqueires de trigo, o que demonstra as dificuldades do cultivo de trigo enfrentado pelos açorianos e a massiva adoção da produção da farinha de mandioca.

No mesmo relatório constam ainda algumas informações sobre a produção agrícola e a área onde era produzido:

O terreno dos Barreiros até a Ponta do Leal é fértil para a mandioca, arroz, milho, feijão, linho e algodão; da ponta do Leal até o Estreito que fica defronte da Vila capital do Desterro, Coqueiros, Itaguaçu e Abrão, suas mandiocas, arroz, milho feijão, cana, algodão e linho, mas há poucas forças para a plantação. Capoeiras e Praia Comprida dão arroz, milho, feijão; no Arraial da Freguesia de São José, são as terras muito fracas e pouco produzem. No Rio Passavinte, são as terras muito boas e dão de tudo [...] ressalta ainda que Picadas do Norte e Maruhy pode se plantar de tudo ${ }^{17}$.

Essas áreas de cultivo em "terras muito boas", nos vales de declives suaves foi alvo, por exemplo, do olhar do viajante inglês John Mawe, que percorreu a região em 1807. Ao se referir ao lugar denominado Picadas, menciona a presença nesse "vale adorável [...] ornado de cottages brancos", de laranjeiras e cafezais A paisagem rural de origem lusa, seria, na visão desse viajante, circunscrita pela existência desse e outros vales contíguos, formando "os limites do território habitado pelos portugueses". Ao Oeste, estariam os indígenas, "aqui chamados bugres" 18 , ocupando as florestas das áreas de serra. Populações que eram cada vez mais marginalizadas em sua constante disputa territorial contra portugueses, principalmente a partir da abertura da estrada ligando Lages ao litora ${ }^{19}$.

Com a fundação de Lages, no século XVIII, que possuía um importante papel geopolítico, assegurando a ocupação portuguesa do planalto sul do Brasil, surgiu a necessidade de se abrirem novas vias de comunicação além do caminho já existente, ligando o Rio Grande do Sul a São Paulo. Um desses caminhos pretendia ligar o litoral com o planalto,

${ }^{17}$ RIBEIRO, 1959, p. 155 apud FARIAS, V. F. de. Op. Cit., p. 120

${ }^{18}$ HARO, M. A. P. de. Ilha de Santa Catarina: Relato de viajantes estrangeiros nos séculos XVIII e XIX. 4a ed. Florianópolis: Ed. da UFSC, Editora Lunardelli, 1996, p. 191

${ }^{19}$ SANTOS, S. C. Índios e brancos no Sul do Brasil: a dramática experiência dos Xocleng. Florianópolis: Edeme, 1973.

Fronteiras: Revista Catarinense de História [on-line], Florianópolis, n.23, p.7-20, 2014. 
saindo de Nossa Senhora do Desterro (atual Florianópolis), com destino ao povoado de Lages, na época pertencente a São Paulo. Caminho que foi aberto na última década do século XVIII ${ }^{20}$.

A abertura desse caminho acabou por transformar não apenas as relações sociais e econômicas entre o litoral e o planalto, mas também a própria paisagem dos espaços por onde este percorria. Sua abertura significava a possibilidade de comércio da produção agrícola e um incremento na economia de São José, além de uma maior ocupação das terras às suas margens ${ }^{21}$.

Essas características moldariam a paisagem josefense por mais de dois séculos, onde o município tornou-se um importante espaço de produção e transformação da mandioca, na época o principal produto agrícola do litoral catarinense. A presença de engenhos era comum nas áreas rurais, produzindo grande quantidade de farinha e derivados. Outro elemento de grande presença nessas áreas era a cana-de-açúcar, destinados à produção de açúcar, melado e cachaça em seus engenhos e alambiques ${ }^{22}$. Nas áreas de encosta a floresta deu lugar a culturas como a banana, além de fornecer lenha para a população local ${ }^{23}$.

Muitas da áreas cuja vegetação original deixou de existir também se prestavam à criação de animais, fato que persistia na entrada do século XX, conforme consta na Chorographia de Santa Catharina, do Alferes de Infantaria José Vieira da Rosa:

É pena não existir, como não existe para o Estado todo, uma estatistica pela qual se podesse conhecer com exactidão o numero d'animaes domesticos.

Entretanto poderemos mais ou menos calcular que os bois e vaccas orcem por uns oito mil, os suínos por vinte mil e que a creação de aves seja de uns cincoenta a sessenta mil cabeças, pois não ha morador que não possua em seu terreno numerosas aves, dentre as quaes são notadas perús, gallinhas, patos e gansos.

\footnotetext{
${ }^{20}$ REITZ, R. Santa Bárbara: primeiro núcleo de colonização alemã em Santa Catarina. Florianópolis: Editora da UFSC, 1992.

${ }^{21}$ BRÜGGEMANN, A. A. Ao poente da Serra Geral: a abertura de um caminho entre as capitanias de Santa Catarina e São Paulo no final do século XVIII. Florianópolis: Ed. da UFSC, 2008.

${ }^{22}$ CAMPOS, N. J de. Op. Cit..

${ }^{23}$ FARIAS, V. F de. Op. Cit.
}

Fronteiras: Revista Catarinense de História [on-line], Florianópolis, n.23, p.7-20, 2014. 
Municipio littoral, o que entre nós quer dizer: constituído por mattos e não campos, não possue para a criação do gado senão os potreiros preparados pelo próprio criador ${ }^{24}$.

A fala de Vieira da Rosa, além de mencionar a criação de gado, traz também algunas informações sobre a paisagem urbana do município, onde era possível vislumbrar também muitos elementos rurais, com pequenas plantações, árvores e criações de animais, na grande maioria aves e suínos.

Essas atividades promoveram a devastação da floresta nativa, tanto nas áreas mais elevadas, onde se encontravam formações da Floresta Ombrófila Densa quanto das formações de restinga. Diferente das intervenções naturais provocadas por chuvas excessivas, tempestades e secas ou mesmo das ações das populações indígenas que habitavam a região antes dos europeus, a abertura de pastos e lavouras provocou danos irreversíveis à fauna e flora locais. A respeito da Mata Atlântica, Warren Dean, comenta que

clareiras abertas por temporais podem levar cem anos para alcançar um estado sucessório maduro, idêntico ao da floresta vizinha. Mesmo então as árvores emergentes de tronco grosso não terão tido tempo para se tornarem gigantes. Clareiras produzidas para abrigar fazendas ou agricultura de grande escala podem impedir o retorno a um estado maduro por tempo muito mais longo ou, talvez, para sempre ${ }^{25}$.

O autor menciona os danos causados pela lavoura de grande extensão. Porém, no caso de diversas áreas de colonização promovidas no Sul do Brasil, da qual a açoriana também faz parte, predominava a pequena propriedade, cujos impactos à vegetação original são semelhantes. A disposição dos terrenos e o reduzido tamanho dos mesmos acarretou no adensamento populacional e no maior uso do solo, tanto para a agricultura quanto para a criação de animais. No caso da ocupação açoriana, a principal característica era a proximidade das famílias em lotes de pequena dimensão, reduzidos ainda mais a partir da partilha por herança ${ }^{26}$. Ocupação que seria acrescida pela instalação de teuto-brasileiros ao longo do século XIX.

\footnotetext{
${ }^{24}$ VIEIRA DA ROSA, J. Chorographia de Santa Catarina. Florianópolis: Typographia da Livraria Moderna, 1905, p. 188

${ }^{25}$ DEAN, W. Op. Cit., p. 32.

${ }^{26}$ PIAZZA, V. Op. Cit.
}

Fronteiras: Revista Catarinense de História [on-line], Florianópolis, n.23, p.7-20, 2014. 
Muitas das dificuldades encontradas pelos imigrantes germânicos que se instalaram na região de São Pedro de Alcântara, a partir de 1829, estavam relacionadas aos aspectos naturais, como o relevo íngreme e o solo com baixa fertilidade, o que fez com que muitas famílias procurassem novas terras, em áreas mais próximas ao litoral, como na Praia Comprida, ao Sul, em Santo Amaro da Imperatriz e ao norte em Biguaçu e Antônio Carlos. Muitos também passaram a viver no Vale do Itajaí ${ }^{27}$.

Esses imigrantes absorveram muitos hábitos dos açorianos no que se refere à agricultura, da mesma forma que os açorianos haviam absorvido dos indígenas. A coivara, assim como o cultivo da mandioca são os mais conhecidos. Muitos também passaram a processar a mandioca, transformando-a em farinha, cujo excedente da produção era comercializado. Os açorianos, por sua vez também incorporaram hábitos trazidos pelos germânicos, como o cultivo da batata e a forte inclusão do suíno na dieta regional ${ }^{28}$.

Mudanças que não são reflexo apenas do contato entre diferentes culturas. Todo um conjunto de mudanças, aceitações e ressignificações de hábitos e costumes possuem também a influência das "forças na natureza". Embora haja uma recusa em se aceitar a existência de um determinismo ambiental, não se pode ignorar a influência do quadro natural na dinâmica das sociedades humanas ${ }^{29}$. Assim o solo, o relevo e o clima, que eram diferentes do ambiente em que essas populações viviam anteriormente, seja nos Açores ou na Europa central, exerceram uma importante influência na adoção de hábitos e costumes por esses novos moradores, no que se refere, por exemplo, a alimentação. Como é o caso da mandioca e do milho, que passaram a compor a dieta dessas populações em detrimento do trigo, alimento comum entre a população européia.

Em locais, como a Praia Comprida, os colonos de origem alemã desenvolveram atividades relacionadas não apenas à agricultura, mas também ao comércio, "onde se tornaram os recebedores dos productos [...] para transportal-os á Capital, nas duas feiras semanaes" ${ }^{30}$. Além das casas de comércio, foram estabelecidos também o transporte por lanchas para a

${ }^{27}$ FARIAS, V. F de. Op. Cit., REITZ, Raulino.Op. Cit.
${ }^{28}$ CAMPOS, N. J de. Op. Cit..

${ }^{29}$ DRUMMOND, J. A. A história ambiental: temas, fontes e linhas de pesquisa. Estudos Históricos. Rio de Janeiro, vol. 4, n. 8, p. 177-197, 1991. p. 181-183.

${ }^{30}$ VIEIRA DA ROSA, J. Op. Cit., p. 311.

Fronteiras: Revista Catarinense de História [on-line], Florianópolis, n.23, p.7-20, 2014. 
Capital, ferrarias, selarias, hospedarias, sapatarias e marcenarias, que aproveitavam os recursos madeireiros da Floresta Ombrófila Densa ${ }^{31}$.

Ponto de ligação importante, não apenas entre a serra e o litoral, mas também entre a ilha de Santa Catarina e o continente, pela Praia Comprida percorriam tropas tanto vindo de Lages quanto das próprias áreas coloniais, que despachavam sua produção para a capital através do trapiche existente no lugar. Isso era comum até a construção da ponte Hercílio Luz na década de 1920. O local foi também local de passagem de viajantes europeus que percorreram Santa Catarina no século XIX, como Robert AveLallemant. Embora o viajante não faça nenhuma menção à população lusoaçoriana que vivia antes da imigração alemã, seu relato ilustra o crescimento populacional dos moradores teuto-brasileiros e as atividades econômicas empreendidas quando este percorreu o litoral e o planalto catarinenses em 1858:

A praia ao norte de São José [sede do município] chama-se Praia Comprida por formar um amplo arco. Aqui mora há muitos anos o "velho Adão" [...]. Então era tudo areia e primitivismo. No entanto Adão abriu ali um pequeno negócio. Os moradores das colônias em formação vinham à casa dele quando traziam seus produtos do mercado ou quando queriam adquirir os artigos da cidade necessários às suas casas; ali se encontravam, ali se conheciam, compravam e vendiam. Os filhos dos colonos cresceram, casaram-se, instalaram-se na vizinhança e atraíram outros alemães. Assim nasceu a Praia Comprida, à esquerda e à direita do velho Adão $[\ldots]^{32}$.

São José apresentava nesse período, conforme aponta Nazareno José de Campos,

duas frentes econômicas, conservando o uso da terra como base [...] desde meados do século XVIII, passando por todo o século XIX e alcançando até as primeiras décadas do século XX. Uma delas é a agricultura, tendo na produção de mandioca $\mathrm{o}$

${ }^{31}$ FARIAS, V. F. de. Op. Cit.

${ }^{32}$ AVÉ-LALlEMANT, R. Viagens pelas províncias de Santa Catarina, Paraná e São Paulo (1858). Belo Horizonte: Itatiaia; São Paulo: Edusp, 1980, p. 127.

Fronteiras: Revista Catarinense de História [on-line], Florianópolis, n.23, p.7-20, 2014. 
elemento principal, geralmente associada à pesca. A outra, de grande importância para a economia regional era a comercialização de gado em pé ou subprodutos, como a tradicional carne seca salgada em mantas, regionalmente conhecida por charque, provenientes do Planalto ${ }^{33}$.

Parte dessa produção agrícola era comercializada atendendo tanto às necessidades do município quanto às da vizinha capital do Estado, do planalto catarinense e mesmo outros Estados do país. Esse comércio e produção agrícola trouxeram representatividade ao município, que no final do século XIX, possuía uma área aproximada de dez mil quilômetros quadrados. Encontravam-se presentes "para fazer funcionar esta engrenagem socioeconômica de produção e prestação de serviços" uma série de profissionais autônomos, como "ferreiros, pedreiros, carpinteiros, seleiros, construtores de embarcações, oleiros, cartorários, artesãos, sapateiros, padeiros, classificados como artistas, os quais, somados aos comerciantes, agricultores, militares, funcionários públicos". Quadro que foi fundamental na dinamização da economia local ${ }^{34}$.

Figura 1: Sede do município, década de 1920. Ao fundo as encostas devastadas para a aberura de lavouras e pastagens.

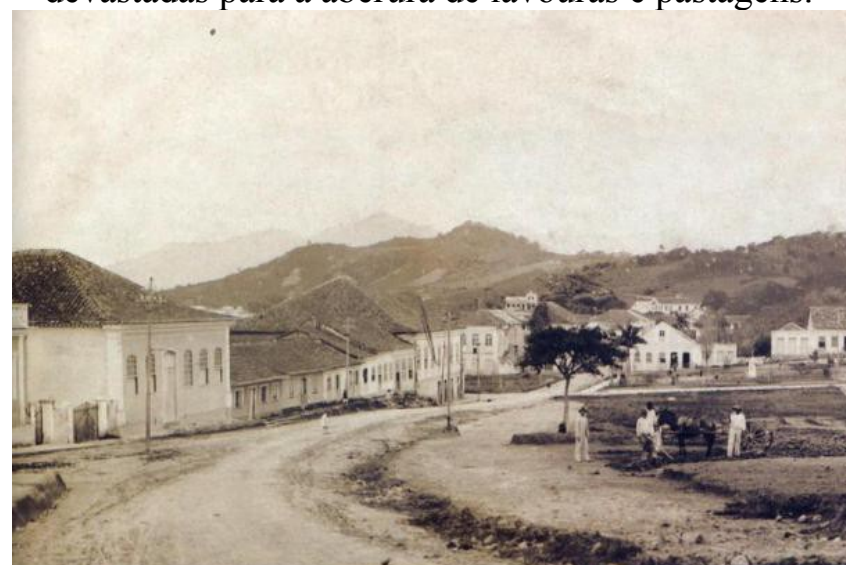

Fonte: Diário Catarinense. Fotos antigas de São José. Disponível em: $<$ http://diariocatarinense.clicrbs.com.br/sc/fotos/fotos-historicas-de-saojose-35671.html>. Acesso em 21 de março de 2014.

\footnotetext{
${ }^{33}$ CAMPOS, N. J. de. Op. Cit.., p. 11.

${ }^{34}$ FARIAS, V. F. de. Op. Cit. p. 124.
} 
A construção da Ponte Hercílio Luz e mais tarde a anexação dos bairros do Estreito e Capoeiras ao município de Florianópolis, afetaram seriamente a economia josefense, que, assim como a região, passava por um momento de estagnação entre as décadas de 1930 a 1950, caracterizadas por um baixo crescimento populacional e econômico. Durante esse período, a cidade passou a viver basicamente de sua proximidade com a capital ${ }^{35}$.

A partir de finais da década de 1950, ganha força um processo ligado ao contexto de transformações capitalistas em curso nos espaços rurais brasileiros visando à transformação da agricultura tradicional, modificando as técnicas de trabalho e a produção do produtor rural. Ganha força um discurso em que o que era considerado "tradicional" passa a ser desqualificado em contraposição ao moderno ${ }^{36}$, em um Estado que possuía na década de 1950 cerca de $75 \%$ da população vivendo no campo ${ }^{37}$. O setor agrícola respondia por $73,4 \%$ da força de trabalho empregada na economia estadual, gerando $48,1 \%$ da renda do Estado nesta mesma década ${ }^{38}$. O atraso se devia ao esquecimento do espaço rural.

Em São José, que na época, possuía, mais de $80 \%$ da população vivendo na área rural na sede e seus distritos ${ }^{39}$, essa presença é percebida não apenas pela proximidade com a capital, mas também pela implantação e atuação de instituições ligadas a esse novo contexto, como uma instituição ligada ao Ministério da Agricultura, e um Campo de Demonstração voltado à produção pecuária selecionada ${ }^{40}$.

Essas mudanças tornaram possível o surgimento de um nova mentalidade na produção agrícola, voltada principalmente ao mercado, diferente da tradicional agricultura voltada à subsistência, com a comercialização de seus excedentes ou a pequena produção mercantil de produtos tradicionais como os derivados da mandioca e da cana-de-açúcar.

\footnotetext{
${ }^{35}$ Idem.

${ }^{36}$ LOHN, R. L.. A cidade contra o campo. In: BRANCHER, A. (orgs). História de Santa Catarina: estudos contemporâneos. 2. ed. Florianópolis: Letras Contemporâneas, 2004. p. 46.

${ }^{37}$ CUNHA, I. J. O salto da indústria catarinense: um exemplo para o Brasil. Florianópolis: Paralelo 27, 1992, p. 30.

38 ABREU, A. Panorama da economia catarinense. In: Ensaios sobre a economia catarinense. Florianópolis: EDEME, 1970.

${ }^{39}$ INSTITUTO BRASILEIRO DE GEOGRAFIA E ESTATÍSTICA. Recenseamento Geral do Brasil (10 de Setembro de 1940). Série Regional, parte XIX - Santa Catarina. Rio de Janeiro: Serviço Gráfico do Instituto Brasileiro de Geografia e Estatística, 1952, p. 73.

${ }^{40}$ CAMPOS, N. J de. Op. Cit.
}

Fronteiras: Revista Catarinense de História [on-line], Florianópolis, n.23, p.7-20, 2014. 
As áreas tradicionais de produção em São José foram se convertendo em em espaços agrícolas voltados diretamente à comercialização. Essa forma de produção, como aponta Nazareno José de Campos, diferencia-se da então praticada por descendentes de açorianos e alemães, pois muitos desses produtores mercantis tem origem em outras áreas (principalmente de municípios próximos, como Águas Mornas, Rancho Queimado, Angelina, São Bonifácio, Alfredo Wagner, Urubici, Urupema, etc.). Esses novos produtores passaram a se dedicar principalmente à produção de hortaliças, como tomate, vagem, pimentão, repolho, couve flor, alface, cenoura, entre outros, com o emprego de instrumentos de trabalho mecanizados e insumos químicos. Por outro lado, os produtores que não se inseriram nesse sistema, passaram a arrendar ou vender suas terras, paulatinamente desaparecendo enquanto produtores rurais. Muitos passaram a compor, pela baixa formação escolar, a mão-de-obra de baixo custo empregada no setor urbano em crescimento, sobretudo a construção civil ${ }^{41}$.

Esse creescimento urbano está atrelado ao o desenvolvimento econômico de Florianópolis a partir das décadas de 1950 e 1960, dentro do contexto dos grandes planos e programas estatais, visando o desenvolvimento econômico ${ }^{42}$. Destacaram-se nesse período a instalação e criação de novos órgãos públicos, como Universidade Federal de Santa Catarina (UFSC), as Centrais Elétricas de Santa Catarina (CELESC) e mais tarde a Eletrosul Centrais Elétricas S.A., que junto com o desenvolvimento do turismo, promoveram um maior fluxo de pessoas rumo a Florianópolis, onde muitas delas passaram a residir em São José. Esse período também passou a registrar o afluxo de moradores de áreas rurais do município em direção aos bairros ${ }^{43}$.

É possível afirmar que a decadência da economia regional entre as décadas de 1930 e 1950, tenha contribuído para a recomposição da floresta em algumas áreas de encosta, como sugere Nazareno José Campos ${ }^{44}$. A regra geral, no entanto, foi a ocupação das encostas antes de sua recomposição com a construção de diversos loteamentos. Essa urbanização passa a alterar, ao longo do seu processo tanto as características físicobióticas quanto sociais, como ressalta Helena Maria Mesquita Balassiano:

\footnotetext{
${ }^{41}$ Idem.

42 SCHMITZ, S. Planejamento estadual: a experiência do Plameg. Florianópolis: UFSC, 1985.

${ }^{43}$ CAMPOS, N. J. de Op. Cit.

${ }^{44}$ Idem.
}

Fronteiras: Revista Catarinense de História [on-line], Florianópolis, n.23, p.7-20, 2014. 
as sociedades, ao criarem aglomerados urbanos, alteraram a paisagem natural preexistente, criando uma paisagem cultural, a qual, por sua vez, vai se modificando gradualmente, no decorrer do tempo. É nesse processo de transformação que as características do lugar - solo, águas, vegetação, ar, paisagem e clima - foram utilizadas como recurso para a construção de um novo ambiente: o meio ambiente urbano ${ }^{45}$.

Meio ambiente urbano cuja construção passa a se verificar em áreas antes predominantemente rurais e que, a partir da década de 1970 passaram a assumir feições urbanas, enquanto áreas urbanizadas tradicionais aumentavam a densidade populacional, acompanhada de variadas intervenções no ambiente, drenando ou retilinizando cursos de rios, aterrando, asfaltando, construindo casas e edifícios, mutilando a paisagem natural por um chão urbanizado.

Essa expansão refletiu no bairro da Praia Comprida, e no surgimento de bairros vizinhos, como Kobrasol, Forquilhinhas e Campinas, devido à proximidade da BR 101, que facilitaria a comunicação com outras regiões do país e com a própria capital. Conforme Nazareno José de Campos,

tal rodovia torna-se um verdadeiro marco, pois, além de valorizar as terras em seu entorno, atrai uma série de atividades e interesses. Daí se origina, entre vários exemplos, a Área Industrial no bairro Fazenda Santo Antônio, que até décadas anteriores dominava em sua área a produção agrícola e a criação de gado; e, no lado oeste da via, o surgimento dos conjuntos habitacionais do $\mathrm{BNH}$, originando os bairros Bela Vista I, II e III, Forquilhinhas e Flor de Nápoles, igualmente áreas de produção agrícola e pastagens com gado em períodos imediatamente anteriores ${ }^{46}$.

${ }^{45}$ BALASSIANO, H. M. M. As favelas e o comprometimento ambiental. In: MESQUITA, O. V; SILVA, S. T. (orgs). Geografia e questão ambiental. Rio de Janeiro: IBGE, 1993.

46 CAMPOS, N. J. de. Op. Cit., p. 18.

Fronteiras: Revista Catarinense de História [on-line], Florianópolis, n.23, p.7-20, 2014. 
Figura 2: Bairro Kobrasol na década de 1970. No canto esquerdo a BR 101. Ao fundo, instalações do Ministério da Agricultura.

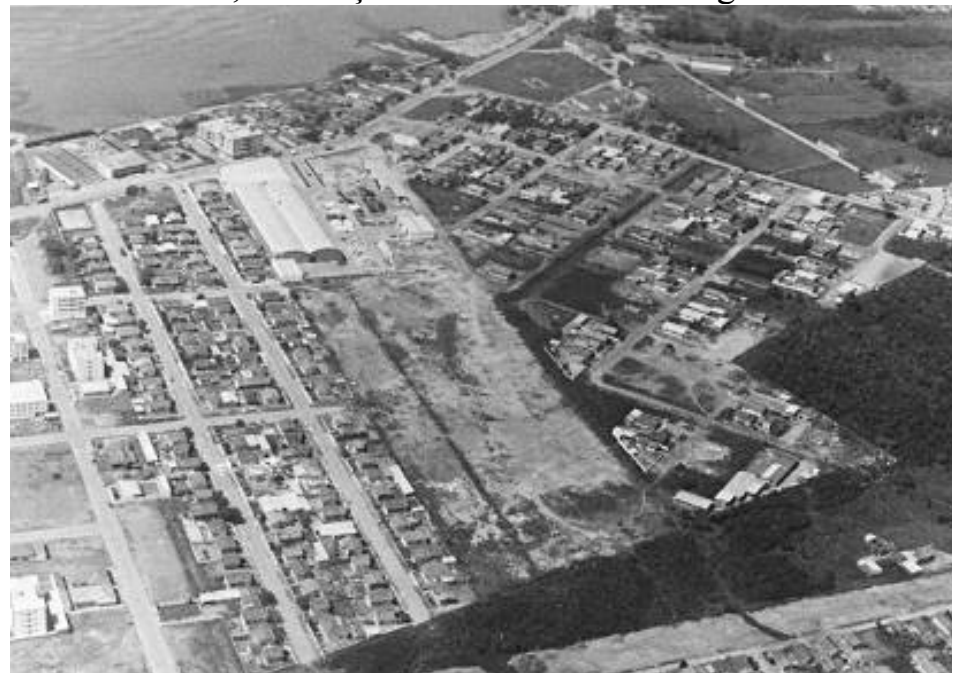

Fonte: Carlos Damião. Disponível em:

$<$ http://carlosdamiao.wordpress.com/tag/fotos-antigas-de-sao-jose-sc/>. Acesso em 21 de março de 2014.

Todo esse processo de transformação da paisagem em São José foi também responsável, no seu decorrer, pelo surgimento de uma série de problemas ambientais no município como um todo. Alguns bairros, como Forquilhinhas e Flor de Nápoles, por se encontrarem em uma área de vale baixo e plano, sofreram com diversas enchentes, enquanto as encostas, descobertas de sua cobertura vegetal, passaram a sofrer com a erosão e desmoronamentos. A retirada da cobertura vegetal, substituída pelo cimento e o asfalto, promoveram a impermeabilização do solo, tornando a região mais suscetível ao alagamento. Isso também é verificado na Praia Comprida, onde algumas áreas próximas a um pequeno córrego que foi canalizado apresentam pontos de alagamento durante chuvas mais intensas. Outros dois problemas são o aumento da poluição, oriundo do intenso tráfego de automóveis, e o aumento da temperatura local, originando assim um microclima, formando ilhas de calor nos espaços onde existe pouca ou nenhuma vegetação. $\mathrm{O}$ efeito da vegetação nas áreas urbanas reflete-se na 
filtragem dos poluentes e na ventilação, tornando o clima local mais ameno $^{47}$.

Ao longo desse período de três séculos, São José, e a região litorânea central do Estado como um todo passaram por um intenso processo de transformações em seu ambiente natural. Se no início a ação era realizada pelo fogo e por golpes de machado, colocando ao chão centenárias árvores da Mata Atlântica, que gradativamente cediam espaço às lavouras e pastagens, o desenvolvimento econômico da capital, com a criação e instalação de diversos órgão públicos e o turismo, trouxe a reboque o crescimento populacional de diversos municípios vizinhos, como São José. A partir dos anos de 1990 o município passou a perder a configuração de "cidade-dormitório", se expandindo, não só nos setores ligados ao comércio (em especial o comércio atacadista, favorecido pela presença da rodovia BR-101), mas também no setor industrial, que se desenvolve às margens da mesma rodovia. Movimento que tem levado a uma urbanização acelerada, modificando a paisagem, onde, em um período inferior a 50 anos, o setor agrícola, que assumia um importante peso na economia local, passou a ocupar um papel periférico, estando cada vez mais distante, em áreas de menor valor imobiliário.

Apesar de todo o rápido e intenso crescimento pelo qual a cidade passou a partir da década de 1990, ainda persistem características rurais na paisagem do município. Estas não se encontram somente nos espaços mais afastados da cidade, mas também nos espaços urbanos, em pastagens com criação de gado bovino e equinos em terrenos baldios ou na beira das estradas, sendo essa uma atividade de uso momentâneo por moradores locais. Existe também a criação em terrenos entre os diversos loteamentos formados a partir de antigas linhas e caminhos para as áreas rurais à espera de um empreendimento ou servindo para a especulação imobiliária, tendendo ao futuro desaparecimento.

\footnotetext{
${ }^{47}$ DUARTE, D. H. S; SERRA, G. G. Padrões de ocupação do solo e microclimas urbanos na região de clima tropical continental brasileira: correlações e proposta de um indicador. Ambiente Construído. Porto Alegre, v. 3, n. 2, p. 7-20, abr-jun. 2003. p. 9.
}

Fronteiras: Revista Catarinense de História [on-line], Florianópolis, n.23, p.7-20, 2014. 